\title{
Tipificação das famílias de oito assentamentos rurais da região de Andradina (SP), com base em diferentes estratégias de produção e comercialização
}

\author{
Antonio Lázaro Sant'Ana ${ }^{1}$ \\ Maria Aparecida Anselmo Tarsitano ${ }^{2}$
}

Resumo: Este artigo propõe uma tipologia das famílias assentadas na região de Andradina (SP), com base nos principais sistemas de produção e de comercialização; e na presença (ou não) de diversificação da renda agropecuária. Os dados empíricos utilizados para a formação dos grupos provêem de questionários sócio-econômicos aplicados a 169 famílias de oito assentamentos e de 80 entrevistas. Os grupos foram comparados entre si, a partir do perfil da família, patrimônio, crédito e assistência técnica, produção para o autoconsumo e renda externa ao lote. A estratégia de aumento da produção e produtividade (da pecuária leiteira) se restringe a menos de um quarto dos produtores, mas outras estratégias são utilizadas pelas famílias, como a diversificação da renda agropecuária e a venda direta ao consumidor ou ao comércio varejista. A associação da diversificação da produção com a utilização, de forma regular, de canais diferenciados de comercialização mostrou-se uma estratégia capaz de aproximar os indicadores deste tipo de produtor em relação aos que se direcionaram para o aumento da produção e da produtividade. Esta constatação é importante, pois, embora não haja contradição necessária entre estas duas estratégias, grande parte das famílias não tem recursos, infra-estrutura e/ou capacitação técnica para trilhar o caminho da intensificação produtiva e outras não têm esse projeto como prioritário.

Palavras-chaves: tipificação das famílias, estratégias, comercialização diferenciada, assentamentos rurais, região de Andradina (SP).

\footnotetext{
${ }^{1}$ Doutor em Sociologia (Unesp). Professor da Unesp Ilha Solteira. E-mail: lazaro@agr.feis.unesp.br

${ }^{2}$ Doutora em Administração de Empresas (USP), Professora Adjunta da Unesp Ilha Solteira. E-mail: maat@agr.feis.unesp.br
} 


\begin{abstract}
This article intends to provide a typology of the families that are settled in the region of Andradina (Sao Paulo state), according to the main production and commercialization systems and to the presence (or not) of agricultural income diversification. The empiric data used to form the groups originate from socioeconomic questionnaires that had been applied to 169 families of eight rural settlements and also from 80 interviews. The groups were compared with each other, starting from the family's profile; patrimony; credit and technical support; self-consumption production; and the lot's external income. The strategy to increase the production and the productivity (dairy cattle) is limited to less than a quarter of the producers, however different strategies had been used by families, such as the diversification of the agricultural income and the direct sale to the consumer or to the retail trade. The association of the production diversification with the use, in a regular way, of differentiated channels of commercialization demonstrated a strategy capable to approximate the indicators of this type of producer comparing with those that focused on increasing the production and the productivity. This verification is important because, even though there is no necessary contradiction among both strategies, a part of the families does not have resources, infrastructure and/or technical qualification to follow the way of the productive intensification and others do not have this project as a priority.
\end{abstract}

Key-words: family tipification, strategies, differentiated commercialization, rural settlements, Andradina region (SP).

Classificação JEL: Q12; Q15.

\title{
1. Introdução
}

Este artigo baseia-se nos resultados de duas pesquisas realizadas em oito assentamentos rurais da região de Andradina $(\mathrm{SP})^{3}$, para propor uma tipologia dos produtores, construída com base nos principais sistemas de produção e de comercialização; e na presença (ou não) de diversificação da renda agropecuária. Os tipos assim formados foram comparados a partir de um conjunto de características, como o perfil da família (ocupação anterior, escolaridade, número de filhos), o patrimônio acumulado, o apoio recebido em termos de assistência técnica e crédito rural, a produção para o autoconsumo e a geração de renda externa ao lote (agrícola e não-agrícola). Embora seja uma proposta preliminar, o interesse é analisar como a organização da produção e da comercialização se inter-relaciona com estas outras variáveis.

${ }^{3}$ Quatro assentamentos (Esmeralda, Orlando Molina, São José II e Timboré) foram investigados em pesquisa que contou com apoio da Fapesp e os outros quatro (Anhumas, Aroeira, Belo Monte e Rio Paraná), apoiada pelo CNPq. 
Este exercício de tipificação poderá trazer alguns elementos importantes para reflexão sobre essas formas de organização da vida e do trabalho, além de contribuir para a geração de propostas que potencializem as experiências bem-sucedidas e evitem algumas dificuldades vivenciadas pelas famílias assentadas.

\section{Assentamentos rurais: perspectivas de análise}

O número de assentamentos criados e de famílias assentadas tem causado controvérsias, em função de discrepâncias entre os dados oficiais (especialmente quando ocorre mudança de governo) e aqueles divulgados pelos movimentos sociais. É inegável, porém, que a partir de meados da década de 90 foi intensificada a criação de assentamentos rurais no Brasil.

Em termos de número de assentamentos, até 2007, foram implantados 7.945 projetos, que ocupam uma área de mais de 77,4 milhões de hectares. Entre 1995 e 2006, o Incra registra o assentamento de 973.560 famílias, sendo que, deste total, 245.061 foram assentadas no período de 2003 a 2006 (INCRA, 2008). Ferreira (2005), no entanto, mostra que pode haver uma defasagem entre a capacidade total dos assentamentos e o número de famílias efetivamente assentadas. Ao citar dados do Sistema Sipra/Incra referentes a maio de 2005, o autor menciona que, na época, apenas $71,2 \%$ do total de lotes disponíveis estavam com famílias regularmente assentadas.

O fato de grande parte das famílias terem sido assentadas em áreas com restrições à produção agropecuária (como o sertão nordestino), ou com problemas de infra-estrutura, fez emergir com maior força análises e questionamentos sobre a qualidade (SPAROVEK, 2003) e os impactos (LEITE et al., 2004; MEDEIROS e LEITE, 2004) da política de assentamentos brasileira. Estes trabalhos, embora utilizem metodologias distintas, mostram alguns aspectos comuns: na grande maioria dos casos, a criação dos assentamentos significou uma melhoria das condições de vida das famílias (alimentação, moradia, auto-estima) e foi importante para os municípios onde estes se instalaram, mas há sérios problemas em termos de ação operacional do governo, em relação à instalação de infra-estrutura básica, à liberação de crédito, à assistência técnica ${ }^{4}$, à falta de implantação do Plano de Desenvolvimento do Assentamento (PDA), entre outros. Além disso, os assentados apresentam problemas de organização para produzir e comercializar a produção.

Deve-se, porém, evitar uma perspectiva teleológica e unívoca da trajetória dos produtores familiares (assentados ou não), em que o ideal seria o produtor

\footnotetext{
${ }^{4}$ O governo Lula aumentou os limites de crédito do Pronaf "A" Investimento e o crédito destinado à habitação e tem buscado prover os assentados de acompanhamento por parte de técnicos de extensão rural, mas, neste caso, predominam contratos temporários com organizações não-governamentais, o que, muitas vezes, prejudica a continuidade do trabalho.
} 
Tipificação das famílias de oito assentamentos rurais da região de Andradina (SP), com base em diferentes estratégias de produção e comercialização

que intensifica a produção, tem maior capacidade de investimento, utiliza técnicas modernas e apresenta alto grau de integração ao mercado, como é, em grande medida, a perspectiva do trabalho realizado pelo Incra em colaboração com a FAO (Organização das Nações Unidas para a Alimentação e Agricultura), sem subestimar, no entanto, os méritos desta pesquisa (INCRA/FAO, 2000).

O desempenho das famílias assentadas não pode fundar-se numa análise que se limita aos aspectos técnicos e monetários, visto que os assentamentos apresentam realidades complexas e dinâmicas, em que uma série de fatores ligados ao contexto regional, às políticas públicas, à organização interna, aos mediadores e aos recursos naturais, também influenciam a situação de cada projeto familiar (BERGAMASCO e FERRANTE, 1998). Por outro lado, a diferenciação resultante destes fatores não é sempre negativa e nem leva necessariamente à desintegração de um projeto. É preciso compreender que o objetivo de um assentamento não é criação de uma comunidade de iguais, pois o conflito é parte constitutiva das relações sociais (MEDEIROS e ESTERCI, 1994).

Este artigo, a partir de uma análise tipológica, procura colocar em debate a questão de que, além do aumento da produção e produtividade, há outras estratégias que podem resultar na melhoria da condição de vida das famílias, tanto do ponto de vista objetivo (alimentação, moradia), como subjetivo (auto-estima, percepção de liberdade para conduzir a produção, a comercialização e os seus projetos de vida).

\section{Metodologia e técnicas da pesquisa}

A pesquisa teve como foco de investigação parte dos assentamentos que são acompanhados pelo GTC (Grupo de Trabalho de Campo) da região de Andradina (SP) do Itesp ${ }^{5}$ (Instituto de Terras do Estado de São Paulo). No total, são 11 assentamentos e 938 famílias assentadas.

Após discussão com técnicos do Itesp e do Incra da região de Andradina, e com base nos objetivos do trabalho, foram excluídos dois assentamentos que, na época da pesquisa (2005/2006), tinham sido implantados há menos tempo (São Joaquim e Terra Livre), e o Primavera, mais antigo, por ter se descaracterizado ${ }^{6}$ parcialmente. Entre os oito projetos restantes, quatro foram pesquisados no âmbito de uma pesquisa financiada pela Fapesp (são eles: Timboré, Esmeralda, Orlando Molina e São José II) e os outros quatro por meio de uma pesquisa financiada pelo CNPq (são eles: Anhumas, Aroeira, Belo Monte e Rio Paraná).

${ }^{5}$ O GTC de Andradina, juntamente com o GTC de Promissão, faz parte da Coordenação Regional VI - Noroeste, cuja sede também é em Andradina.

${ }^{6}$ No caso do Assentamento Primavera, as famílias receberam o título definitivo dos lotes, o que resultou na venda de parte ou da totalidade de vários lotes para terceiros que, por sua vez, transformaram essas áreas em sítios/chácaras de lazer. 
Com base na análise das informações disponíveis sobre os assentamentos da região, concluiu-se que a aplicação do questionário junto a uma faixa de 20 a $30 \%$ do total de famílias de cada assentamento escolhido seria suficiente para contemplar a diversidade existente (no total foram pesquisados 169 produtores). As pesquisas adotaram metodologias semelhantes, a única diferença é que, no caso da Fapesp, as famílias pesquisadas representaram de 20 a $30 \%$ do total de cada assentamento (mais de 100 famílias, 20\%, de 50 a 100 famílias, 25\%, e menos que 50 famílias, 30\% ), enquanto para o CNPq foram pesquisadas 30\% das famílias de cada assentamento (Tabela 1). Em todos os assentamentos analisados, a área predominante dos lotes está em torno 15 a 16 ha.

Tabela 1. Características gerais dos assentamentos pesquisados.

\begin{tabular}{lccc}
\hline Assentamento / Município & $\begin{array}{c}\text { Área Total } \\
(\mathbf{h a})\end{array}$ & $\begin{array}{c}\text { Famílias Total } \\
(\mathbf{n} \mathbf{0})\end{array}$ & $\begin{array}{c}\text { Famílias } \\
\text { Pesquisadas (no) }\end{array}$ \\
\hline Anhumas (Castilho) & $1.350,9$ & 63 & 20 \\
Aroeira (Guaraçaí) & 873,3 & 40 & 12 \\
Belo Monte (Andradina) & $1.588,0$ & 74 & 22 \\
Rio Paraná (Castilho) & $2.208,7$ & 92 & 28 \\
Esmeralda (Pereira Barreto) & $2.096,3$ & 85 & 21 \\
Orlando Molina (Murutinga do Sul) & $1.511,9$ & 77 & 19 \\
São José II (Guaraçaí) & 877,6 & 39 & 12 \\
Timboré (Andradina/Castilho) & 3364,7 & 176 & 35 \\
\hline Total & $13.871,4$ & 646 & 169 \\
\hline
\end{tabular}

Fonte: Itesp, 2006.

Figura 1. Regiões de governo do estado de São Paulo, com destaque para a região de Andradina, onde situam-se os oito assentamentos pesquisados.

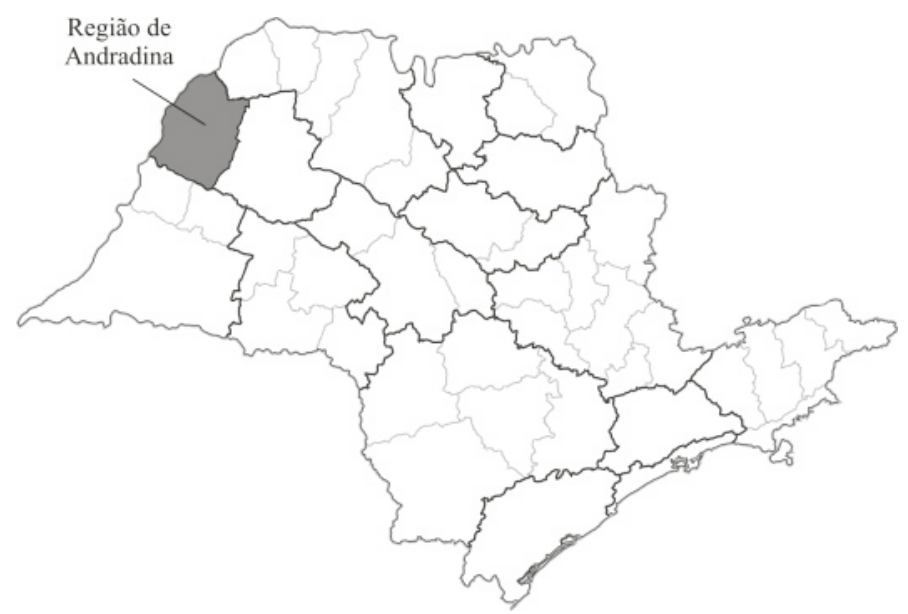

Fonte: www.cidadespaulistas.com.br (modificado pelo autor). 
As famílias também deveriam atender algumas condições prévias para serem incluídas na primeira fase da pesquisa (aplicação dos questionários): a família deveria estar desenvolvendo alguma atividade produtiva, residir na área há pelo menos três anos e não apresentar irregularidade grave junto ao Incra (como ter abandonado o lote ou estar arrendando a área para pessoas externas ao projeto de assentamento). Para selecionar as famílias, o Itesp ${ }^{7}$ elaborou listas de produtores que se enquadravam nestas condições e, a partir dessas listas (maiores do que o número de famílias que deveriam responder ao questionário), procedeu-se a pesquisa em cada um dos assentamentos, procurando contemplar as diferentes atividades agropecuárias existentes e, atendido este critério, a escolha foi aleatória.

No questionário realizado, foram levantados os dados básicos sobre a família, a infra-estrutura do lote, a produção, a tecnologia e os canais de comercialização utilizados pelos produtores, além de verificar o acesso ao crédito, à assistência técnica e a outras formas de apoio recebidas.

Após a tabulação e a análise dos dados dos questionários, foram escolhidas diferentes experiências em termos de atividades produtivas, formas de comercialização e geração de renda, e entrevistadas (depoimento gravado) 80 famílias entre os produtores que responderam ao questionário (47,3\% do total). $\mathrm{O}$ objetivo das entrevistas foi aprofundar a compreensão das estratégias adotadas pelas famílias no que diz respeito aos sistemas de produção e de comercialização.

Em todos os casos buscou-se levantar, também, informações sobre o papel das políticas públicas (em seus diversos níveis) em termos de crédito e outros incentivos ea contribuição dos órgãos de assistência técnica e extensão rural e de empresas privadas.

\section{Tipificação das famílias pesquisadas}

O objetivo de tornar mais inteligíveis determinados processos sociais levou a busca por esquemas classificatórios que visam apreender as semelhanças e diferenças que lhes são constitutivos e característicos.

De acordo com o Incra/FAO (1999, p. 24) a tipificação dos sistemas de produção ${ }^{8}$ permite identificar as distintas formas pelas quais os produtores organizam suas atividades, em função de diferenças:

\footnotetext{
${ }^{7}$ Solicitou-se ao técnico do Itesp responsável pela assistência técnica em cada um dos assentamentos a elaboração de uma lista dos assentados que atendiam essas condições e também manteve-se contato com os representantes sindicais e de movimentos sociais (como o MST) da região, visando apreender outros aspectos relevantes não contidos no material do Itesp e nas indicações de seus técnicos.

${ }^{8}$ O sistema de produção é entendido como "o resultado das decisões tomadas pelo agricultor e/ou seu grupo familiar quanto à escolha das atividades e ao emprego dos fatores produtivos dentro de suas limitações ecológicas, econômicas e culturais" (PORTO, 2003, p. 104), portanto não se limita aos aspectos técnicos da produção. Porto (2003) faz uma extensa revisão bibliográfica sobre os temas de sistemas de produção e sistemas agrários.
} 
(...) tanto no que se refere ao acesso à terra, aos demais recursos naturais, à informação, aos serviços públicos, aos mercados e ao crédito, quanto no que diz respeito ao nível de capitalização, aos recursos financeiros disponíveis, aos conhecimentos adquiridos, à disponibilidade de mão-de-obra, etc. (INCRA/FAO, 1999, p. 24).

A análise dos sistemas de produção pode auxiliar, também, a compreensão das diferentes racionalidades envolvidas nas escolhas dos produtores.

Vários trabalhos que analisam os sistemas de produção utilizam um grande número de indicadores e/ou métodos estatísticos para identificar as semelhanças/diferenças entre os sistemas e formar os grupos (FERREIRA, 2001; CALCANHOTO, 2001; MANGABEIRA et al., 2002). Na medida em que estão, muitas vezes, tratando com o conjunto altamente heterogêneo de produtores rurais de um determinado local, estas ferramentas ajudam a compor os grupos, a partir de um grande número de indicadores. No caso de uma categoria social mais precisa e relativamente mais homogênea, como os assentados da reforma agrária na região de Andradina, optou-se por realizar a tipologia com alguns dados considerados chaves e que foram identificados a partir das informações levantadas no questionário. Posteriormente, foi realizada a análise das características de cada tipo em relação a um conjunto de outros parâmetros também investigados no questionário.

Esta operação sempre envolve decisões com certo grau de arbitrariedade e riscos de simplificação excessiva da realidade. É desejável, portanto, que a tipificação seja complementada por abordagens qualitativas que reintroduzam as particularidades e a complexidade presente na realidade, o que se buscou fazer cotejando as diversas características que emergiram da análise dos dados do questionário, com as informações detalhadas colhidas nas entrevistas.

O objetivo da tipificação das famílias pesquisadas, assentadas na região de Andradina, foi compreender as diferentes estratégias de produção e comercialização e as relações destas com as características da família, com a construção de um dado patrimônio a partir da produção no lote e de políticas públicas, e com outras estratégias dos produtores, como as rendas não-agrícolas e o autoconsumo.

O recorte realizado teve, portanto, como base as características dos produtores em relação aos principais sistemas de produção, incluindo os diferentes tipos de inserção no mercado. A tipificação das famílias assentadas na região de Andradina permitiu visualizar algumas características comuns aos produtores nos oito assentamentos, assim como fez emergir algumas diferenciações não perceptíveis, quando são analisados os produtores pesquisados em cada assentamento específico.

Para a construção da tipologia, foram considerados parâmetros ligados aos sistemas de produção e comercialização, e a existência (ou não) de diversificação da renda agropecuária. Considerou-se um lote diversificado aquele que produz três ou mais produtos cujo destino predominante é a comercialização. 
Em termos de sistemas de produção, o principal é aquele que se apóia na pecuária leiteira, mas, nos assentamentos pesquisados, há diferenciações que se pode dividir esquematicamente em três níveis de tecnificação.

Um primeiro nível tecnológico da pecuária leiteira caracteriza-se pela: formação de novas gramíneas em piquetes com rotação intensiva e adubação; suplementação com silagem de milho e/ou cana no período seco; utilização de ração concentrada em cocho individual, de acordo com a produção de cada vaca, durante todo o período de lactação; uso de reprodutor especializado em leite (ou inseminação artificial) para formação de novas matrizes no próprio lote; e escrituração das atividades (como o controle leiteiro e reprodutivo). São assentados com produção (tanto no período das águas como no da seca) e produtividade acima da média do conjunto de produtores pesquisados.

O segundo nível tecnológico tem como características: a formação de piquetes de maiores dimensões, às vezes a partir do pasto já existente e com adubação irregular ou sem adubação; a suplementação com cana/napier, "briquete" (produto à base de casca de algodão) e às vezes silagem de milho no período seco; a distribuição de ração concentrada em pequena quantidade para todas as vacas em lactação, sem distinção, via de regra, só no período seco; o uso de reprodutor zebuíno ou, às vezes, adoção temporária de reprodutor especializado em leite; e a maior parte das matrizes de reposição é adquirida de outros produtores.

O terceiro nível tecnológico da pecuária leiteira apresenta como características: a adoção de pastagens com poucas divisões; a suplementação parcial com cana/napier ou "briquete" no período seco; a distribuição de pequena quantidade de ração concentrada somente em casos emergenciais; a adoção de reprodutor zebuíno (visando a comercialização do bezerro); maior parte das matrizes de reposição formadas a partir do próprio rebanho do lote (o que é problemático devido à utilização do reprodutor típico de gado de corte).

Embora não represente todas as características de cada nível tecnológico, adotou-se dois indicadores sintéticos que pudessem expressar seus resultados: a produção e a produtividade da pecuária de leite. Estes indicadores também foram escolhidos por permitir comparar as diferentes estratégias dos produtores, dividindo-os em dois segmentos ou grandes grupos: aqueles que adotam como principal estratégia a melhoria dos níveis técnicos da atividade leiteira, apresentando produção e produtividade acima da média entre os produtores pesquisados e aqueles que estão com estes índices abaixo da média e centram suas ações em outras estratégias.

O segundo indicador que contribuiu para formação dos grupos, embora na maioria dos casos inclua a pecuária leiteira (do universo pesquisado, apenas três produtores não produzem leite), refere-se ao grau de diversificação da renda agropecuária, avaliada a partir da produção agropecuária destinada à comercialização. A diversificação inclui as culturas anuais, como algodão e milho, semi-perenes como mandioca, quiabo e abacaxi, e também outras olerícolas e 
frutas, a maior parte plantadas em pequenas áreas e comercializadas diretamente ao consumidor ou ao comércio varejista das cidades próximas. No caso de animais, cria-se porcos, carneiros e galinhas em pequenas quantidades, que servem para o autoconsumo da família, mas que, em vários casos, a maior parte é destinada à comercialização por meio dos canais diferenciados referidos. Há, também, produtores que buscam diversificar a renda por meio do processamento de produtos (a maior parte proveniente do lote, mas, em alguns casos, com matéria-prima externa), como a fabricação de doces em compota e caldas, rapadura, pé-de-moleque, farinha de mandioca e polvilho, pães, entre outros.

Entre os produtores que diversificam, mas apresentam produção e/ou produtividade abaixo da média no caso da pecuária de leite, utilizou-se dois critérios distintivos: o primeiro associa a diversificação da produção à utilização de canais diferenciados de comercialização (diretamente ao varejo e/ou ao consumidor), enquanto o segundo diz respeito à diversificação da produção sem a utilização de formas diferenciadas de comercialização. Ainda entre os produtores que diversificam e utilizam canais diferenciados de comercialização, realizou-se outra subdivisão, distinguindo um grupo em que esta comercialização é eventual e outro que adota a venda direta ao varejo e/ou ao consumidor de forma regular ou freqüente (em alguns casos, os produtos comercializados desta maneira são a principal fonte de renda da família).

Inicialmente pretendia-se considerar a combinação (ou não) da renda agropecuária e as rendas não-provenientes do lote, mas, nos assentamentos pesquisados, essa variável não apresenta diferenças significativas entre os diversos grupos.

A partir destes critérios foram constituídos os seguintes grupos ${ }^{9}$ :

\section{A) Produção, Produtividade e Diversificação}

\section{(PP-D): 23 famílias}

- produção de leite acima da média em ambos os períodos do ano (a média é de 75 litros/dia nas águas e 50 litros/dia na seca);

- produtividade maior que a média dos produtores pesquisados (a média é de 6 litros/vaca/dia);

- diversificação da produção agropecuária comercializada e/ou utilização de venda direta ao consumidor e/ou ao varejo ${ }^{10}$.

\footnotetext{
${ }^{9}$ Cabe lembrar que os critérios da pesquisa excluíram um possível sexto grupo, constituído pelas famílias que não estão conseguindo produzir nos lotes ou que estão com alguma irregularidade grave junto ao Incra.

${ }^{10}$ Apenas três não diversificam a produção agropecuária, realizando apenas a comercialização diferenciada, enquanto dez produtores combinam ambas as estratégias.
} 
- Tipificação das famílias de oito assentamentos rurais da região de Andradina (SP),

com base em diferentes estratégias de produção e comercialização

\section{B) Produção e Produtividade Sem Diversificação}

\section{(PP-SD): 17 famílias}

- produção de leite acima da média em ambos os períodos do ano (a média é de 75 litros/dia nas águas e 50 litros/dia na seca);

- produtividade maior que a média dos produtores pesquisados (a média é de 6 litros/vaca/dia);

- produção agropecuária não-diversificada e não-utilização de venda direta ao consumidor e/ou ao varejo.

C) Comercialização Diferenciada Regular e Diversificação da Renda (CDreg-DR): 23 famílias

- produção de leite abaixo da média em ao menos um dos períodos do ano e/ou produtividade menor do que a média;

- diversificação da produção agropecuária comercializada;

- utilização de venda direta ao consumidor e/ou ao varejo de forma regular ou freqüente.

D) Comercialização Diferenciada Eventual e Diversificação da Renda (CDev-DR): 46 famílias

- produção de leite abaixo da média em ao menos um dos períodos do ano e/ou produtividade menor que a média;

- diversificação da produção agropecuária comercializada;

- utilização de venda direta ao consumidor e/ou ao varejo de forma eventual.

E) Diversificação da Renda Sem Comercialização Diferenciada (DR-SCD): 41 famílias

- produção de leite abaixo da média em ao menos um dos períodos do ano e/ou produtividade menor que a média;

- diversificação da produção agropecuária destinada à comercialização, mas sem utilizar canais diferenciados para a venda dos produtos;

F) Sem Diversificação da Renda e Sem Comercialização Diferenciada (SDR-SCD): 19 famílias

- produção de leite abaixo da média em ao menos um dos períodos do ano e produtividade menor que a média;

- não realiza comercialização diferenciada;

- renda agropecuária não-diversificada; 
O Diagrama 1 traz um resumo esquemático da formação dos grupos, permitindo visualizar os critérios utilizados em conjunto.

Após a divisão dos grupos, foram comparadas as características destes em relação aos seguintes parâmetros: ocupações anteriores do titular de lote; número de filhos no lote com mais de 14 anos; escolaridade do titular; escolaridade dos demais membros da família; características da moradia; veículos e equipamentos presentes no lote; água encanada e sanitário internos à residência; número de produtos destinados ao autoconsumo; número de animais (bovinos, suínos, caprinos e ovinos, e aves); utilização de financiamento na última safra; utilização de assistência técnica pública; e presença de renda externa ao lote (Quadro 1).

Diagrama 1. Critérios para a formação dos grupos.

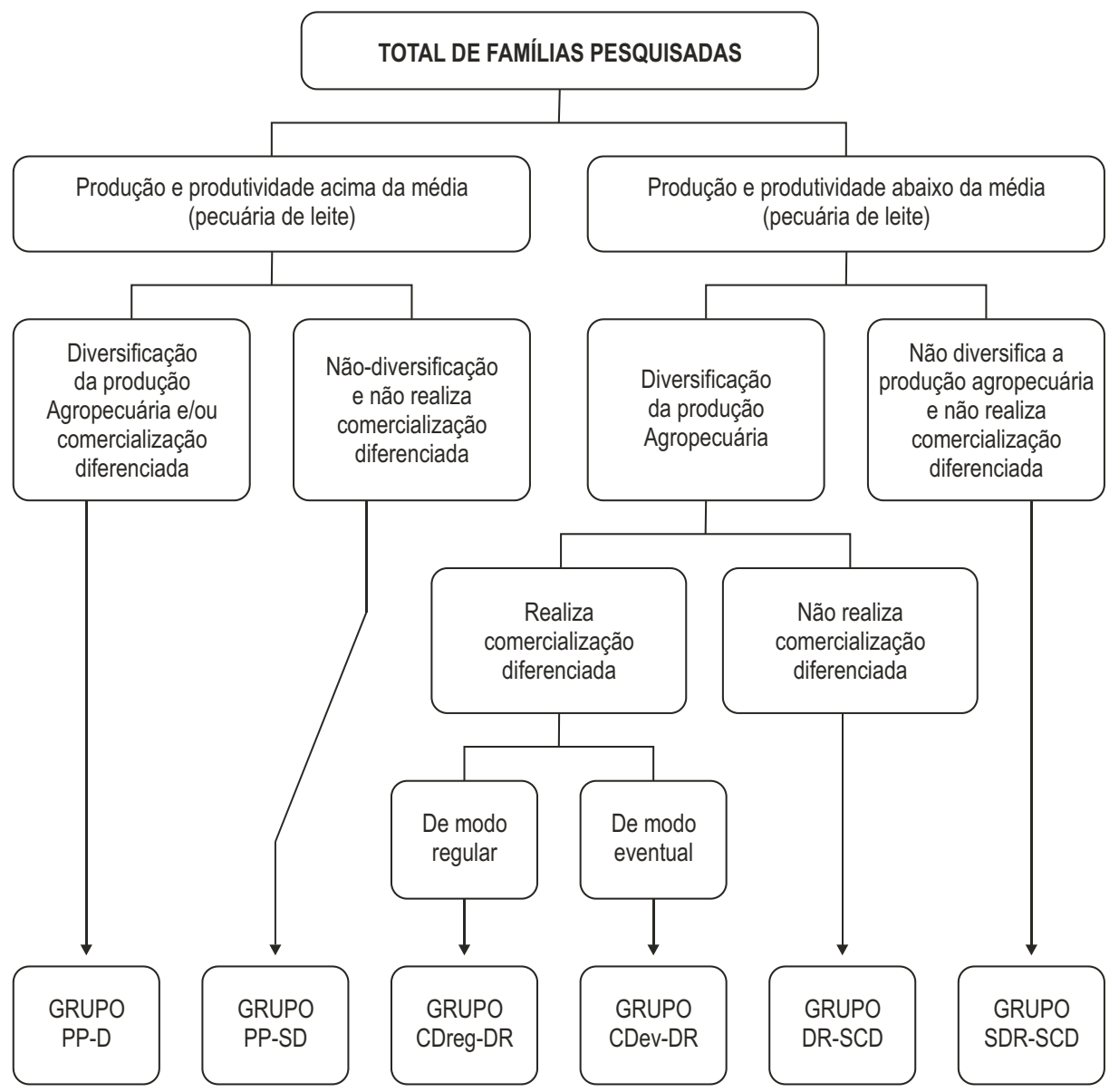


626 - Tipificação das famílias de oito assentamentos rurais da região de Andradina (SP), com base em diferentes estratégias de produção e comercialização

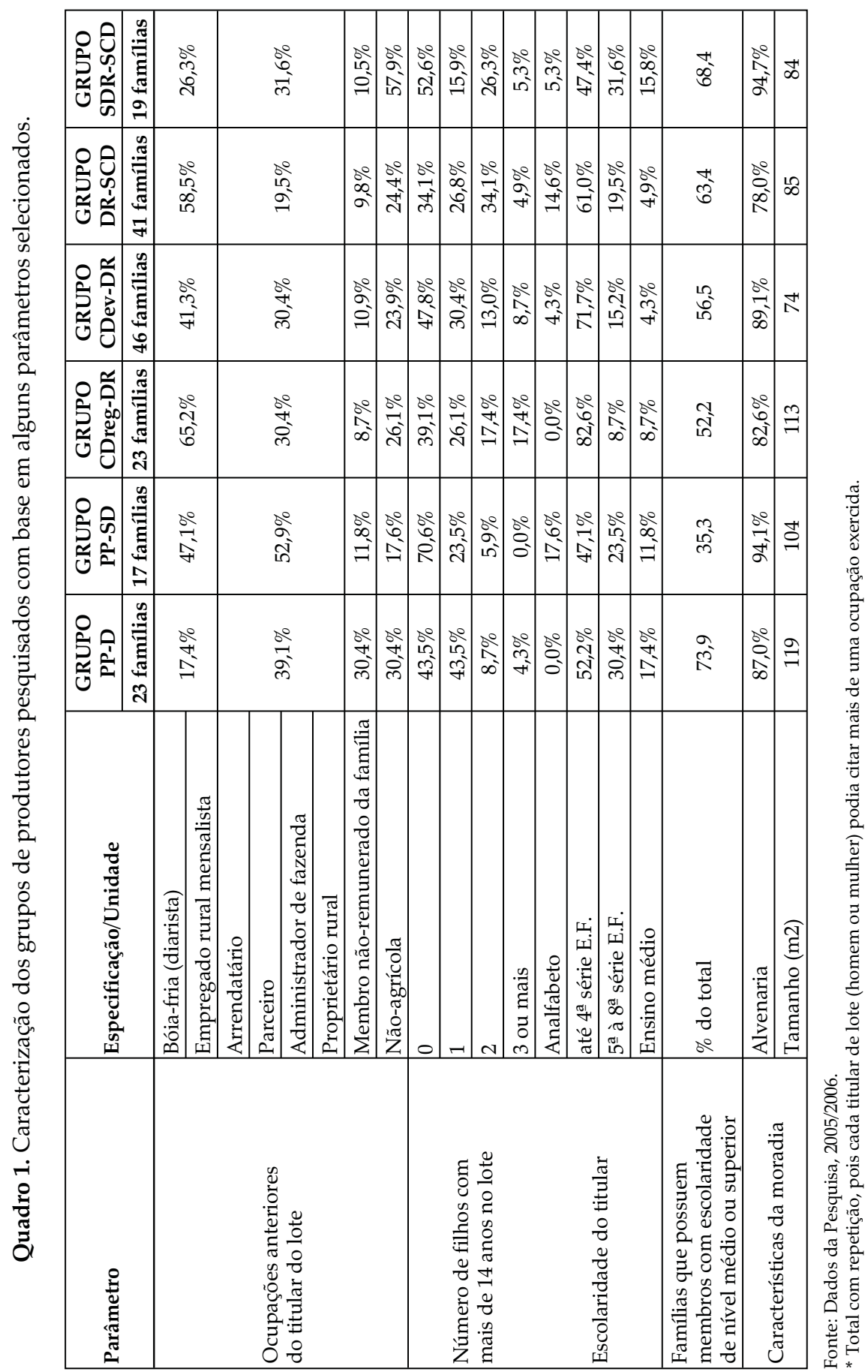




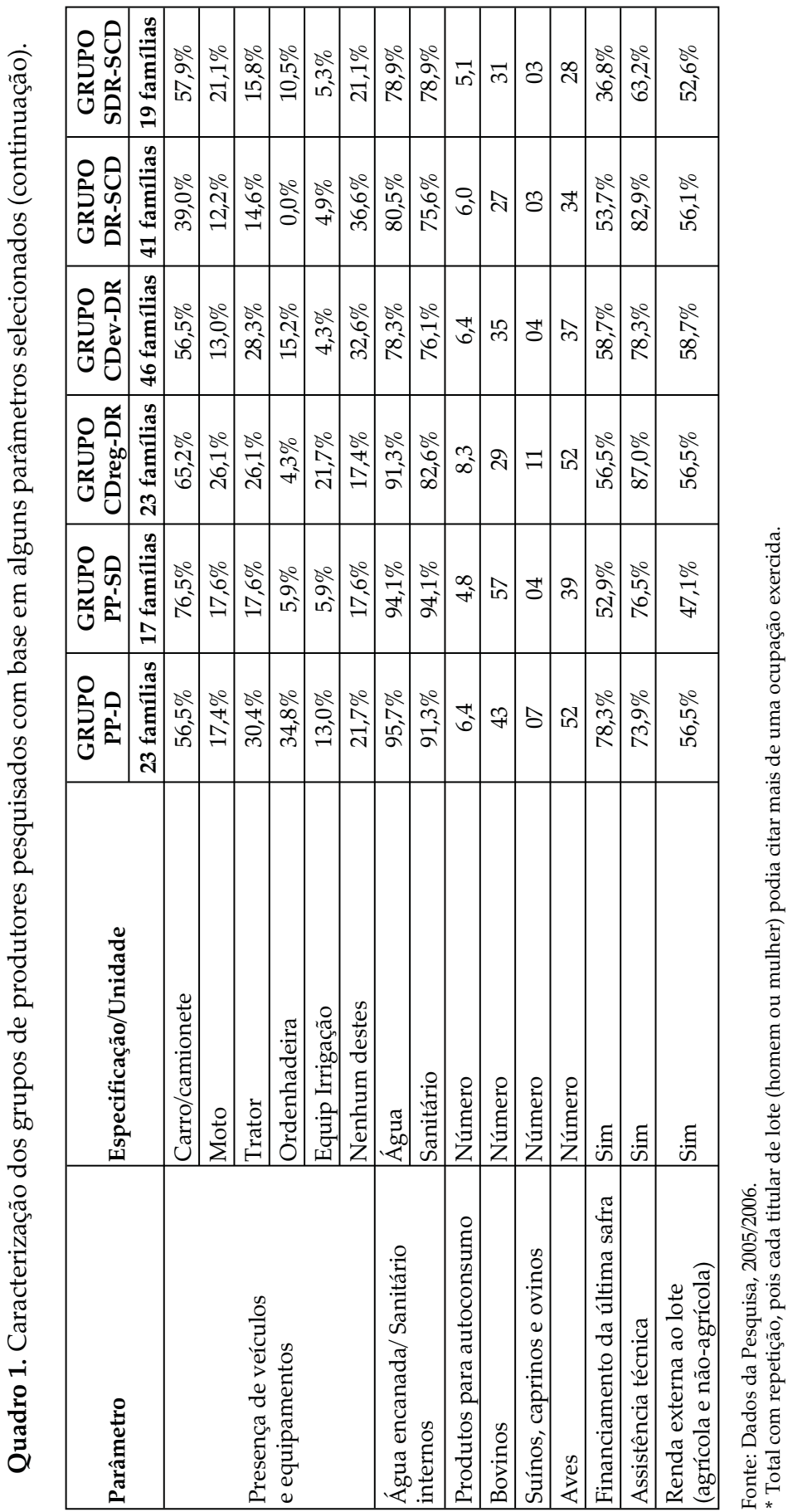

RESR, Piracicaba, SP, vol. 47, no 03, p. 615-636, jul/set 2009 - Impressa em outubro 2009 
A análise comparativa dos grupos não indicou diferenças muito marcantes para o conjunto dos parâmetros, embora em alguns itens específicos estas sejam nítidas. Em parte, as diferenças não são muito acentuadas porque alguns itens analisados tiveram influência de políticas públicas que atingiram de maneira relativamente uniforme o conjunto dos assentados (moradia de alvenaria, água e sanitários internos e assistência técnica), o que não deixa de ser um fator positivo constatado.

Há, no entanto, algumas diferenças qualitativas que foram observadas no trabalho de campo e nas entrevistas, como o estágio e o tipo de acabamento da residência, e em relação ao acompanhamento técnico. Embora o percentual de produtores que recorrem a algum tipo de assistência técnica (pública) seja semelhante em quase todos os grupos (variou de $74 \%$ a $87 \%$ em cinco grupos somente no Grupo SDR-SCD é um pouco menor, $63,2 \%$ ), a avaliação difere de modo significativo, mesmo dentro de um mesmo assentamento, como se pode observar nessas avaliações sobre o Itesp:

O Itesp nós não podemos reclamar. O Itesp é 100\%. Tudo o que vai acontecer, ah, liga lá, 'não, nós vamos amanhã lá resolver' [sic], e agora o novo técnico que tá [sic] hoje não pode falar mal dele, porque ele é muito bom. Se precisar, ele larga tudo, a não ser se não tiver carro [sic]. O Itesp não ajuda mais por causa de carro [sic], mas o técnico vem aqui, a gente não pode reclamar (S-RLO- ESMERALDA).

O Itesp não tem sido muito a favor da gente não, porque tem muita coisa no Itesp que tem que estar correndo atrás, andar procurando. O agrônomo, aqui mesmo vem muito pouco [sic], esse ano não apareceu agrônomo aqui não [setembro] (EAC -ESMERALDA).

Estes dois depoimentos e outros coletados nas entrevistas mostram que há uma diferenciação da assistência técnica nos assentamentos. Alguns produtores recebem um acompanhamento relativamente freqüente (e também demandam), enquanto outros têm um contato somente esporádico com os técnicos. As razões destas diferenças comportam um outro trabalho, mas envolvem diferenças em termos de receptividade das recomendações técnicas por parte dos assentados (o extensionista tende a privilegiar aqueles que adotam mais as prescriçóes), empatia ou problemas em termos de relacionamento pessoal ou político, dedicação do técnico, entre outras. É interessante notar que o Grupo CDreg-DR (Comercialização Diferenciada Regular e Diversificação da Renda) obteve o maior índice de acompanhamento e, neste caso, é possível afirmar que são produtores que demandam o técnico com freqüência e se dispõem a adotar inovações, especialmente fora do padrão predominante, que é a pecuária de leite. Alguns programas do Itesp, como de implantação de estufas, kits de irrigação e de 
padaria, pomares domésticos, curso de comercialização e o de transporte para determinadas feiras de produtores, embora limitados, também têm beneficiado os assentados que buscam diversificar suas atividades.

Os integrantes dos dois grupos com produção e produtividade acima da média são compostos de produtores mais estruturados em termos de atividade leiteira, com produção média no período seco de 106 litros/dia e alguns com produtividade acima de 10 litros por vaca/dia e controle bastante rigoroso da alimentação do rebanho, como pode ser verificado no depoimento a seguir da filha de um produtor:

Bom, aqui, todas as vacas que são ordenhadas, elas [sic] comem ração $21 \%$ [de proteína]. As vacas comem por produção e eu tenho umas com produção de 20 litros é [sic] tantos quilos [de ração] (...). O volumoso daqui é [também] controlado, não é à vontade no cocho [sic]. A gente usa o método que cada vaca come no seu cocho com o pescoço amarrado. Então, eu vou lá, eu faço mais ou menos assim: cada vaca eu passo uma fita para pesagem, mais ou menos eu sei o peso dela [sic], 500, 550 quilos. Em cima desse peso, eu calculo a alimentação e a proteína total. Pela proteína eu tiro o volumoso, o silo que o animal está comendo [sic] (J-JAM - BELO MONTE).

O Grupo PP-D (Produção, Produtividade e Diversificação), com 23 famílias, reúne duas características importantes. Ao mesmo tempo em que está investindo na melhoria da produção e produtividade da pecuária leiteira, este grupo também tem buscado diversificar a produção e, eventualmente, a venda dos produtos em canais diferenciados de comercialização. Portanto, seria esperado que o Grupo PP-D se destacasse em relação aos demais, especialmente nos aspectos materiais (patrimônio). Embora isso aconteça, as diferenças não são muito nítidas, visto que, em vários parâmetros, há outro grupo, além do Grupo PP-D, se destacando dos demais. A área média construída, a escolaridade dos membros da família, o percentual de produtores que possuem ordenhadeiras mecânicas e o percentual de produtores que tomaram crédito rural são os poucos itens em que os integrantes do Grupo PP-D se sobressaem em relação aos demais. Em outros aspectos, como a infra-estrutura sanitária de água da casa, a quantidade relativa de tratores, há um ou mais grupos com desempenho semelhante. Observa-se, também, que o Grupo PP-D não apresenta, no entanto, um padrão uniforme em termos de veículos e equipamentos - um percentual significativo dos produtores $(21,7 \%)$ não apresenta nenhum dos bens selecionados.

O Grupo PP-SD (Produção e Produtividade Sem Diversificação), composto de 17 famílias, caracteriza-se por priorizar a pecuária leiteira (como o Grupo PP-D), mas desenvolve outras atividades somente quando complementares à atividade 
- Tipificação das famílias de oito assentamentos rurais da região de Andradina (SP), com base em diferentes estratégias de produção e comercialização

principal (como o milho para silagem ou rolão ${ }^{11}$ ) ou apenas marginalmente. Este grupo é o que apresenta maior percentual de titulares do lote com experiência anterior de administração de seus negócios na área rural (52,9\%), embora quase o mesmo percentual também tenha trabalhado como empregado de fazenda ou bóia-fria (47,1\%). Mais de $70 \%$ das famílias não possuem filhos com mais de 14 anos no lote, o que pode ter influenciado na decisão de investir apenas em uma atividade. Em relação à escolaridade, é o grupo com maior percentual de analfabetos e com menor percentual de membros da família que estudaram até o ensino médio ou superior. Destacam-se pelo número relativo de veículos (carros e camionetes) e pelo número total médio de bovinos, mas está próximo aos grupos com menor quantidade relativa de tratores, ordenhadeiras, equipamentos de irrigação e é o grupo com menor quantidade de produtos destinados ao autoconsumo da família e das atividades produtivas.

O Grupo SDR-SCD (Sem Diversificação da Renda e Sem Comercialização Diferenciada), formado por dezenove famílias, embora seja menos estruturado do ponto de vista produtivo, destaca-se em alguns parâmetros como o grau de escolaridade: $47,4 \%$ dos titulares de lote estudaram mais de quatro anos (no Grupo CDreg-DR foram apenas 17,4\%) e 68,4\% das famílias possui outro(s) membros que estudaram (ou estão estudando), no mínimo, até o ensino médio (apenas o Grupo PP-D apresenta um percentual um pouco maior, 73,9\%). Em termos de veículos e equipamentos, também não há diferenças significativas em relação aos demais grupos, mas em outros itens apresenta uma condição mais desfavorável, como no caso do número médio de produtos destinados ao autoconsumo da família ou das atividades do lote; do número de pequenos animais (o número de bovinos é semelhante aos demais grupos de baixa produção e produtividade da pecuária de leite), do acesso a financiamentos $(36,8 \%)$ e à assistência técnica $(63,2 \%)$ ou apresentam situaçóes que podem dificultar o trabalho no lote, como o alto percentual de titulares que exerciam atividades não-agrícolas antes de serem assentados (57,9\%) e de famílias sem filhos com mais 14 anos no lote (52,6\%). Entre as famílias deste grupo que possuem dois ou três filhos no lote (31,6\%), em 77,8\% dos casos pelo menos um deles trabalha fora (nos outros grupos este percentual é menor). A condição intermediária desse Grupo SDR-SCD parece indicar que estratégias não-agrícolas ou externas ao lote (até mesmo de filhos que não residem no lote) podem estar desempenhando um papel importante para a manutenção das famílias.

Entre os produtores que apresentam produção e produtividade da pecuária leiteira abaixo da média ou que não desenvolvem esta atividade (poucos casos) mas que procuram diversificar a renda agropecuária, o Grupo DR-SCD (Diversificação da renda sem comercialização diferenciada), composto por 41

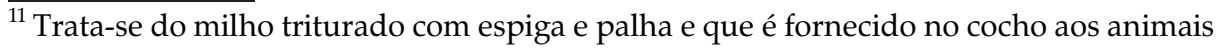
isoladamente ou acompanhado de outro produto. 
famílias, é o que apresenta menor percentual de integrantes com veículos e equipamentos e maior percentual de famílias que não possui nenhum destes bens $(36,6 \%)$. Também é o grupo com menor percentual de moradia de alvenaria e de número médio de bovinos. A maioria dos produtores que não utiliza canais diferenciados de comercialização, como os integrantes deste Grupo, tem direcionado seus esforços de diversificação para as culturas anuais como milho e algodão, mas, como estas culturas tem apresentado problemas freqüentes de produtividade (seca) e/ou de preços, os integrantes deste grupo têm enfrentado dificuldades até maiores que aqueles que não diversificam.

O Grupo CDev-DR (Comercialização Diferenciada eventual e Diversificação da Renda) é o mais numeroso, com 46 famílias, e é, depois do Grupo PP-SD, aquele que possui menor percentual de dois ou mais filhos (maiores de 14 anos) morando no lote (apenas $21,7 \%$ do total de famílias). Também é o grupo com menor área média construída. Destaca-se por ser o grupo com maior percentual de famílias com tratores $(28,3 \%)$, mas, ao mesmo tempo, 32,6\% dos integrantes não têm veículos ou equipamentos analisados.

Entre os grupos analisados, o que mostrou resultados mais interessantes foi o CDreg-DR (Comercialização Diferenciada regular e Diversificação da Renda). Com 23 famílias, esse grupo apresentou cerca de dois terços $(65,2 \%)$ dos titulares de lote que tinham como ocupação anterior a categoria empregado rural diarista ou mensalista e, embora uma parte $(30,4 \%)$ tivesse exercido alguma atividade de gerenciamento, a maioria não tinha este tipo de experiência. Também apresentou o menor nível de escolaridade $(82,6 \%$ estudaram no máximo até a quarta série do ensino fundamental, mas, curiosamente, este é o único grupo sem analfabetos). Apesar destas características aparentemente restritivas, na época da pesquisa, este grupo produzia várias culturas e criações, algumas exigentes em conhecimentos técnicos (como olerícolas, frutas, apicultura e processamento de produtos) e também desenvolvia atividades de comercialização direta, o que envolve habilidades de planejamento da produção, de negociação e de relacionamento cotidiano com os clientes. Estes dados evidenciam que a falta de experiência administrativa e mesmo o baixo grau de escolaridade não impedem o desenvolvimento de opções criativas em termos do sistema de produção e de comercialização adotados pelas famílias (em alguns casos os filhos assumem as tarefas mais complexas, que exigem maior nível de educação formal).

O Grupo CDreg-DR destaca-se também em vários itens em relação aos demais, incluindo aqueles com produção e produtividade acima da média. Isso porque o grupo apresenta características superiores ou semelhantes aos referidos grupos no caso da área média da casa $\left(113 \mathrm{~m}^{2}\right)$; percentual de veículos (carro/camionete, moto e trator); equipamentos de irrigação; número médio de produtos para o autoconsumo (8,3 por família): número médio, por família, de suínos, caprinos e ovinos (11 cabeças) e aves (52 cabeças). Estes dados indicam 
que a diversificação da produção para a comercialização também tem reflexos diretos na quantidade de produtos para o autoconsumo.

As privações sofridas pelo trabalho precário e de baixa remuneração podem estimular estratégias criativas de sobrevivência, como o caso do depoimento a seguir de uma família em que o pai trabalhava como motorista antes de ser assentado e que, na época da pesquisa, comercializava em torno de 600 quilos de doce de leite por mês (ao comércio varejista e ao consumidor). Inicialmente, a filha desse assentado relata o momento anterior à entrada no assentamento:

Nós viemos para cá porque nós tinha [sic] umas cabeças de gado na cidade e o meu pai trabalhava na firma. Então, nós, só filha mulher [sic] ter que pastorar o gado; revezava um pouco na parte da manhã [sic], ficava pastorando o gado dentro da cidade [sic], outra parte depois da escola ia pastorar [sic]. Então meu pai achou que estava sacrificando muito as filhas.

Em seguida, ela descreve como iniciaram a produção/processamento e a forma como conseguiu iniciar a comercialização:

(...) como eu falei para a minha mãe, a gente tinha que arrumar um jeito para sobreviver aqui no sítio. Aí tentamos fazer doce, aí [sic] ela falou: 'ah, o doce não vai mostrar para ninguém...' [sic]. Um dia fomos na reunião do Itesp e falei para a minha irmã que ia parar nas barraquinhas [na margem da Rodovia Marechal Cândido Rondon] e ia conversar [sic], mas ela não gostou (...), chamei meu pai (...) [sic]. A gente ia mostrando [o doce aos clientes] e pouquinho, pouquinho [sic], a gente chegou a entregar 30, 40 vidros [de doce], aí o pessoal gostou. (S-RLO- ESMERALDA).

Neste Grupo CDreg-DR, há alguns produtores que não produzem leite ou que não tem na atividade leiteira sua principal fonte de renda. Um dos produtores que faz feira justifica assim a sua opção:

Eu andei tirando leite uns 3, 4 anos, mas todo dia aquela vida: madrugada e arreia a carroça, leva esse leite, mais tarde cuidar de bezerro. No tempo da seca tem que mexer com cana, fazer ração para tratar dessas vacas, problema de água também é difícil... [sic]

Mas na feira o senhor levanta que horas? [pesquisador]

Mais lá é duas vezes por semana e você vai quando quiser e o leite não [sic], você tem que estar lá todo dia [no caso do leite] (JBC - RIO PARANÁ).

Embora pareça só a procura de menor penosidade do trabalho (produtores que fazem duas ordenhas também reclamam de nunca poderem se ausentar da propriedade por mais do que algumas horas), há a questão de poder administrar 
com maior liberdade o seu tempo de trabalho. Este mesmo produtor, ao relatar a venda direta que realiza nos ranchos de lazer próximos ao assentamento no Rio Paraná, indica outros motivos que sustentam sua opção:

(...) sempre vou para a beira do rio dia de semana [sic]. Eu pego o carro e vou para a beira do rio, levo mandioca, pinha, quiabo, feijão de corda, o que levar vende [sic] (...). Tem gente que não tem coragem de fazer isso, tem que chegar na casa, ficar chamando, 'oh, você quer comprar isso' [sic] (...) eu sou marreteiro, você sabe como é [sic]. Tem que ter um pouco de costume né? [sic]. Eu até gosto de fazer isso; faz amizade, em qualquer lugar da região, perguntar do J. do Rio Paraná [sic], todo mundo conhece (JBC - RIO PARANÁ).

O ser marreteiro significa gostar de negociar, de realizar vendas ou mesmo trocas não-monetárias ${ }^{12}$ e, ao mesmo tempo, aparece o desejo de formar amizades, tornar-se conhecido, além de conhecer outras pessoas fora do restrito círculo de trabalho e de relações do assentamento.

O fato do Grupo PB-SDR ter um alto percentual de famílias que tinham exercido preponderantemente (ou unicamente) atividades não-agrícolas parece ter influenciado no seu desempenho produtivo no lote, mas, em uma análise geral dos grupos e com base nas informações colhidas nas entrevistas, ficou evidente que, mais do que a atividade anterior, foram importantes os bens que a família possuía ao entrar no lote e que foram vendidos ou serviram para iniciar o trabalho, formando as bases para aumentar a produção e a produtividade. Um assentado do Orlando Molina assim se pronuncia sobre os recursos e os bens que possuía ao entrar no lote:

(...) porque, quando você tem um início, se torna mais fácil para você gerenciar e tocar seus projetos né? [sic]. A partir do momento que você não tem nada, como gera alguma coisa? Você não consegue gerar nada, você fica parado no tempo, não vai [sic]. Quando você tem alguma coisa para começar, você sai bem na frente dos demais que ainda vão aguardar recurso do governo federal, talvez alguns projetinhos do governo do Estado [São Paulo] para dar início e a gente já inicia, bem aplicado [sic], bem gerenciado, sai na frente (JETS- ORLANDO MOLINA).

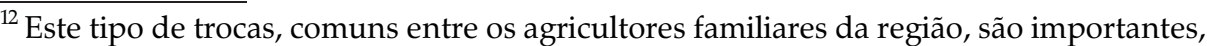
pois, como mostram Ribeiro e Galizoni (2007), ao tratar da catira, um sistema de trocas realizadas pelos agricultores do norte de Minas Gerais, trata-se de uma forma ativa de se relacionar com o mercado, produzindo "constantemente minúsculas estratégias de convívio, que variam de acordo com situações, regiões, condições de acesso aos recursos, cultura e economias locais" (RIBEIRO e GALIZONI, 2007, p.67).
} 
Os resultados também indicaram que em todos os grupos, mais da metade das famílias contam com rendas externas ao lote, desde aposentadorias, como trabalho agrícola (dos filhos) ou atividade não-agrícola de algum membro da família. Ao contrário do que julgam alguns analistas, cada vez fica mais evidente que atividades externas (a maioria não-agrícola) não resulta no abandono da agricultura. Freqüentemente, contribuem para dinamização da produção no lote. Um produtor aposentado e cuja esposa trabalha como agente de saúde no Assentamento Timboré comenta sobre o papel das rendas não-agrícolas:

Vamos dizer que elas [as rendas não-agrícolas] não são importantes, é a minha salvação. Elas, digamos, que seriam o alicerce, a garantia da gente não passar fome, porque olha [sic] eu tô [sic] mudando para a pecuária. Se não tivesse essa renda, eu não podia tá [sic] mudando para a pecuária. Porque a pecuária me dá lucro uma vez por ano, porque meu planejamento é comprar o bezerro, deixar aí um ano e abater e vender [sic] (JMC-TIMBORÉ).

A análise geral dos grupos mostra que a estratégia de aumento da produção e produtividade de um determinado sistema de produção, embora possa sofrer influência de determinadas condições prévias (como a ocupação e os bens anteriores à entrada no lote) e tenha reflexos importantes em outros aspectos da produção e da vida das famílias, não é a única estratégia capaz de manter a família no lote em condições dignas. Há produtores que estão investindo em formas diferenciadas de comercialização e na diversificação produtiva, e que também têm conseguido, embora com maior dificuldade, apresentar alguns parâmetros semelhantes ao grupo que tem centrado seus esforços nos aumentos da produção e da produtividade. Mesmo entre os integrantes que investem na intensificação da produção, obtém maior destaque aqueles que também buscam diversificar a produção, como o caso de famílias dos assentamentos São José II e Aroeira, que cultivam abacaxi de forma parcelada durante todo o ano.

\section{Considerações finais}

Este trabalho realizou uma tipificação dos produtores de oito assentamentos rurais da região de Andradina (SP) com base nos principais sistemas de produção utilizados. Em seguida o trabalho buscou comparar os grupos a partir de um conjunto de características referentes ao perfil das famílias, ao patrimônio disponível, ao acesso ao crédito e à assistência técnica e a outras estratégias, como a presença de rendas externas ao lote e a quantidade de produtos destinados ao autoconsumo. 
A análise dos dados obtidos permitiu constatar que, além da estratégia de aumento da produção e produtividade (no caso, da pecuária leiteira), há outras estratégias que são colocadas em prática por um grupo expressivo de produtores, como o desenvolvimento de atividades que visam à diversificação da renda agropecuária. A predominância da pecuária leiteira e os problemas que produtores tiveram com culturas anuais (algodão e milho) tornaram quase invisíveis os esforços de diversificação da produção agropecuária, desenvolvidos por um grande número de produtores, visto que, na maior parte dos casos, os valores monetários gerados não são expressivos, mas, cabe destacar, são importantes para equilibrar o orçamento familiar, ao lado de outras rendas (externas ao lote e/ou não-agrícolas).

A associação da diversificação da produção com a utilização regular de canais diferenciados de comercialização (venda direta ao consumidor e/ou ao varejo) mostrou-se uma estratégia capaz de aproximar os indicadores deste grupo em relação ao que se direcionou para o aumento da produção e da produtividade. Evidentemente que não há contradição necessária entre estas duas estratégias, mas cabe destacar que uma parte dos produtores não tem recursos, infra-estrutura e/ou de capacitação técnica para trilhar o caminho da intensificação produtiva e outros não têm este projeto como prioritário. Mesmo o grupo com maior dificuldade em termos de produção apresenta vários parâmetros de padrão de vida semelhantes aos demais grupos, em função do caráter relativamente uniforme de algumas políticas públicas e porque parecem desenvolver estratégias alternativas à produção no lote.

\section{Referências Bibliográficas}

BERGAMASCO, S. M. P. P., FERRANTE, V. L. S. B. No reino da modernização: o que os números do Censo da reforma agrária (não) revelam. In: Os assentamentos de reforma agrária no Brasil. Brasília: Editora Universidade de Brasília, 1998, p. 170-204.

CALCANHOTTO, F. A. Diagnóstico e Análise de Sistemas de Produção no Município de Guaíba/RS: uma abordagem agroeconômica. 2001. 220p. Disponível em: http://www.ufrgs.br/pgdr/dissertacoes/dissetpubecorural.html. Acesso: 21/06/2007.

FERREIRA, B. A reforma agrária no governo Lula. Balanço: 2003 a 2005. Reforma Agrária, São Paulo, v. 32, n. 1, p. 11-35, 2005.

FERREIRA, J. R. C. Evolução e Diferenciação dos Sistemas Agrários do Município de Camaquã-RS: uma análise da agricultura e suas perspectivas de desenvolvimento. 2001. 192p. 
INCRA. Números da Reforma Agrária. Disponível em: www.incra.gov.br. Acesso em 29/01/2008.

INCRA/FAO. Análise diagnóstico de sistemas agrários: guia metodológico. Brasília: INCRA/FAO - Projeto de Cooperação técnica, 1999. 65p.

INCRA/FAO. Novo retrato da agricultura familiar: o Brasil redescoberto. Disponível em: <http://www.incra.gov.br/sade>. Acesso em: 8 abr. 2000.

LEITE, S. et al. Impactos dos Assentamentos: um estudo sobre o meio rural brasileiro. Brasília: IICA/NEAD; São Paulo: Ed. Unesp, 2004. 392p.

MANGABEIRA et al. J. A. C. Tipificação dos sistemas de produção rural: a abordagem da análise de correspondência múltipla em Machadinho d'Oeste-RO. Campinas: Embrapa, Circular Técnica n.8, 2002. 28p.

MEDEIROS, L. S., ESTERCI, N. Introdução. In: MEDEIROS et al. Assentamentos rurais: uma visão multidisciplinar. São Paulo: Editora da Universidade Estadual Paulista, 1994, p.11-26.

PORTO, V. H. F. Sistemas agrários: uma revisão conceitual e de métodos de identificação como estratégias para o delineamento de políticas públicas. Cadernos de Ciência \& Tecnologia, Brasília, v. 20, n. 1, p. 97-121, jan./abr. 2003

RIBEIRO, E.M.; GALIZONI, F. M. A arte da catira: negócios e reprodução familiar de sitiantes mineiros. Revista Brasileira de Ciências Sociais, vol.22, n. 64, p. 65-74, jun. 2007.

SPAROVEK, G. A qualidade dos assentamentos da reforma agrária brasileira. Projeto de Cooperação Técnica MDA/FAO, 2003. 204p. Disponível em: http://www.ufrgs.br/pgdr/textosabertos/textospublicos.htm Acesso em 22/06/2007. 